\title{
Associations of apolipoprotein $E$ exon 4 and lipoprotein lipase S447X polymorphisms with acute ischemic stroke and myocardial infarction
}

\author{
Larry Baum ${ }^{1, *}$, Ho Keung $\mathrm{Ng}^{2}$, Ka Sing Wong ${ }^{1}$, \\ Brian Tomlinson ${ }^{1}$, Timothy Hudson Rainer ${ }^{3}$, \\ Xiangyan Chen ${ }^{2}$, Wing Sze Cheung ${ }^{2}$, Jinling \\ Tang ${ }^{4}$, Wilson Wai San Tam ${ }^{5}$, William \\ Goggins $^{6}$, Cindy See Wai Tong ${ }^{1}$, Daniel Kam \\ Yin Chan ${ }^{7}$, G. Neil Thomas ${ }^{8}$, Ping Chook ${ }^{1}$ and \\ Kam Sang Woo ${ }^{1}$ \\ ${ }^{1}$ Department of Medicine and Therapeutics, \\ ${ }^{2}$ Department of Anatomical and Cellular Pathology, \\ ${ }^{3}$ Accident and Emergency Medicine Academic Unit, \\ ${ }^{4}$ Hong Kong Branch of the Chinese Cochrane \\ Center, \\ ${ }^{5}$ Department of Community and Family Medicine, \\ ${ }^{6}$ Center for Epidemiology and Biostatistics, \\ Chinese University of Hong Kong, Shatin, Hong \\ Kong \\ ${ }^{7}$ Department of Age Care and Rehabilitation, \\ Bankstown Health Service, University of New South \\ Wales, New South Wales, Australia \\ ${ }^{8}$ Department of Community Medicine, University of \\ Hong Kong, Pokfulam, Hong Kong
}

\begin{abstract}
Background: Because apolipoprotein E (apoE) and lipopoprotein lipase (LPL) polymorphisms interact with each other and with other factors to affect lipid metabolism, we sought to determine their separate and combined effects in association with ischemic vascular disease.

Methods: We performed a case-control study of 816 subjects: 246 acute ischemic stroke patients, 234 acute myocardial infarction patients, and 336 controls. $A P O E$ exon 4 and LPL S447X genotypes were determined.

Results: $A P O E \quad \varepsilon 2$ and $\varepsilon 4$ homozygotes were increased in stroke $(4.5 \%$ vs. $1.0 \%, p=0.008)$, while in myocardial infarction the $\varepsilon 4$ allele was increased $(12.6 \%$ vs. $9.5 \%, p=0.006)$ but $\varepsilon 2$ was decreased (3.7\% vs. $12.1 \%, p=0.000006)$. For subjects with either $A P O E \varepsilon 2$ or $\varepsilon 4$ alleles, $L P L X$ alleles were increased in vascular disease $(O R=2.2, \mathrm{p}=0.01)$. $L P L X$ alleles displayed opposite tendencies toward association with disease when subjects were divided by sex, smoking, or $A P O E$ genotype. Meta-analysis and regression analysis of previous studies supported the sex and smoking dichotomies.
\end{abstract}

*Corresponding author: Larry Baum, Department of Medicine and Therapeutics, Chinese University of Hong Kong, Shatin, Hong Kong

Phone: +852-26323146, Fax: +852-26373852

E-mail: Iwbaum@cuhk.edu.hk
Conclusion: This is the first report of an association of vascular disease with an interaction of $A P O E$ exon 4 and $L P L S 447 X$ genotypes. Therefore, APOE genotypes and $L P L S 447 X$ interactions with apoE, sex, and smoking may affect the risk of myocardial infarction and ischemic stroke.

Keywords: apolipoprotein E; ischemic; lipoprotein lipase; polymorphism; smoking.

\section{Introduction}

Polymorphisms in the lipid metabolic genes apolipoprotein $\mathrm{E}(A P O E)$ and lipoprotein lipase $(L P L)$ have been associated with ischemic cerebrovascular and cardiovascular disease (1-14). A polymorphism in exon 4 of $A P O E$ has three common alleles $-\varepsilon 2, \varepsilon 3$, and $\varepsilon 4$ - coding for E2, E3, and E4 isoforms, respectively. $A P O E \& 4$ increases serum cholesterol and vascular disease risk, while apoE $\varepsilon 2$ lowers cholesterol levels $(8-12,15)$. LPL helps to clear triglyceride (TG)rich particles from the circulation $(16,17)$. The LPL S447X polymorphism, which truncates two C-terminal amino acids from the LPL protein, is associated with increased LPL protein secretion and plasma postheparin activity, as well as decreased plasma TG (17-20). The $X$ allele has been associated with reduced risk of vascular disease $(1-3,5-7,17)$.

Because apoE and LPL polymorphisms interact with each other to affect TG and high-density lipoproteincholesterol (HDL-C) levels $(19,20)$, as well as interacting with other factors such as sex or smoking to influence lipid levels $(5,14,18-22)$, we conducted a case-control study of these genetic and clinical factors in acute ischemic stroke and acute myocardial infarction (MI) patients. Associations suggested by the resulting data led us to analyze previous studies for confirmation or refutation of these results.

\section{Materials and methods}

\section{Subjects}

Research with humans was carried out according to the principles of the Declaration of Helsinki. The hospital's institutional Review Board approved the study, and patients or their relatives gave informed consent. All subjects were Hong Kong Chinese. Following admission to the acute stroke unit of a general regional hospital, the Prince of Wales Hospital, Shatin, Hong Kong, 246 consecutive acute ischemic stroke patients were recruited from January 2002 to November 2003. Patients were hospitalized for cerebral infarction 
within 7 days of symptom onset. Brain computed tomography (CT) was performed within $24 \mathrm{~h}$ of admission. CT evidence of stroke was a requirement for inclusion in the study. Patients with past history or CT feature of primary intracerebral hemorrhage were excluded. In addition, magnetic resonance imaging was performed for $90 \%$ of patients. Ultrasound carotid duplex, extracranial and transcranial Doppler (TCD) ultrasound, and electrocardiography were performed routinely for cerebral infarction patients at this hospital. Patients were assessed by a neurologist to confirm the diagnosis of stroke.

From community centers for the elderly, 225 elderly people (aged 65-74 years) were recruited, originally for a study of the effects of exercise. Subjects with known cardiovascular disease or stroke, dementia, uncontrolled/newly diagnosed hypertension, or impaired mobility were excluded from the controls, as were those who were regularly performing exercise. An additional 111 elderly controls (aged at least 60 years) without known cardiovascular disease, stroke, or dementia were recruited from outpatient clinics of the Prince of Wales Hospital and United Christian Hospital.

Also recruited were 234 acute $\mathrm{Ml}$ patients admitted to the coronary care unit of the Prince of Wales Hospital between 1998 and 2002. Patients were not excluded on the basis of age or sex. Diagnostic criteria for acute MI were as follows: characteristic clinical presentation of precordial pain for more than half an hour; pathological $\mathrm{Q}$ wave, ST elevation or T wave inversion in the electrocardiograms, with subsequent evolutionary changes; and an unequivocal rise in the aspartate aminotransferase (SGOT) level to over $45 \mathrm{lU} / \mathrm{mL}$ on one of the three successive days, with the highest level at least twice the lowest one in those with borderline elevation.

Age, sex, serum lipid concentrations, and vascular risk factors, including hypertension, diabetes mellitus, and smoking habit, were collected from controls or during acute admission for patients. Status as a current, former, or never smoker was determined by asking each subject for his/her self-assessment. To measure lipids, fasting blood samples were taken from patients the day after admission or from controls. Hypertension was defined as systolic blood pressure (SBP) $>140 \mathrm{~mm} \mathrm{Hg}$ or diastolic blood pressure (DBP) $>90 \mathrm{~mm} \mathrm{Hg}$ on at least two occasions, or treatment with blood pressure-lowering medication. Diabetes was defined as fasting plasma glucose $>7.0 \mathrm{mmol} / \mathrm{L}$. Levels of TG (enzymatic method without glycerol blanking), total cholesterol (TC) (enzymatic method), and HDL-C (dextran sulfate-magnesium chloride precipitation) were measured on a Hitachi analyzer (Hitachi, Tokyo, Japan), and low-density lipoprotein-cholesterol (LDL-C) was calculated using Friedewald's formula, except when TG was greater than $4.5 \mathrm{mmol} / \mathrm{L}$. The precision performance of these assays was within the manufacturer's specifications. Blood pressure was measured in stroke patients after they had settled in the wards. Data were not available on passive smoking for all subjects or on SBP and DBP for MI patients.

Cholesterol and blood pressure are typically reduced following $\mathrm{MI}(23,24)$. In addition, many coronary artery disease (CAD) patients took lipid-lowering statins, and some nonhypertensive CAD patients took CAD drugs that may also lower blood pressure ( $\beta$-blockers and nitrate). Therefore, we did not use blood pressure or lipid data gathered from $\mathrm{MI}$ patients.

\section{Analysis}

$L P L$ gene exon 9 was amplified by polymerase chain reaction (PCR) using an annealing temperature of $55^{\circ} \mathrm{C}$ and primers
TATTCACATCCATTTTCTTC and GTCAGCTTTAGCCCAGAATG (25). Mnll restriction-enzyme digestion overnight at $37^{\circ} \mathrm{C}$ and separation by $12 \%$ polyacrylamide gel electrophoresis revealed fragments of 28 and $127 \mathrm{bp}$ for the $447 X$ allele, allowing determination of the three possible genotypes (SS, SX,XX).

The fourth exon of $A P O E$ was amplified by a two-step nested PCR using primers as previously described (26). The six possible $A P O E$ genotypes $(\varepsilon 2 / \varepsilon 2, \varepsilon 2 / \varepsilon 3, \varepsilon 2 / \varepsilon 4, \varepsilon 3 / \varepsilon 3, \varepsilon 3 / \varepsilon 4$, $\varepsilon 4 / \varepsilon 4)$ were determined by digestion with Hhal restriction enzyme digestion overnight at $37^{\circ} \mathrm{C}$ and separation by $12 \%$ polyacrylamide gel electrophoresis as previously described (27).

SPSS version 11.5 and Epi6 (World Health Organization, Geneva, Switzerland) were used for data analysis. Differences in continuous variables were examined using Student's t-test or (for Table 4) ANCOVA. Because the distribution of TG levels was skewed, $\log _{10}$ TG was used for comparisons. $\chi^{2}$ Analysis was used to compare distributions of categorical variables. $p$-Values were not corrected for multiple comparisons, and therefore readers should interpret results with due caution until confirmed by other studies.

For multiple logistic regression, factors with the highest $p$ value or which caused deviation from a good fit (i.e., $p<0.05$ in the Hosmer and Lemeshow test) were removed until a value of $p<0.1$ was reached for the remaining factors. Factors that were then used for further adjustments shown in Table 5 are listed in the legend to Table 5.

For meta-analysis, all published case-control studies of ischemic heart disease or stroke were collected by searching PubMed using the keywords lipoprotein lipase, polymorphism, and any of the following: stroke, cardiovascular, infarction, and cerebrovascular. Relevant articles identified were also examined for citations to relevant case-control studies. Meta-analysis was performed using the random effect model of DerSimonian and Laird, with odds ratios weighted by the number of subjects in each group.

\section{Results}

\section{Patient characteristics}

Mean age was matched between stroke patients and controls, although $\mathrm{Ml}$ patients were younger (Table 1). Stroke patients were more often male, current smokers, and had higher TG, more diabetes, and higher blood pressure than controls. MI patients were more often male, current smokers, or former smokers than were controls.

\section{Genotypes}

Stroke, MI, and control groups were tested for HardyWeinberg equilibrium. For each subject group, both $A P O E$ and $L P L$ genotypes were in equilibrium.

In stroke, examination of combinations of genotypes suggested that $A P O E \& 2$ and $\varepsilon 4$ homozygotes were increased (Table 2). MI patients had a different distribution, with more $\varepsilon 4$ and fewer $\varepsilon 2$ alleles. Among subjects with hypertension, $\varepsilon 4$ alleles were increased in both stroke and $\mathrm{Ml}: \mathrm{p}=0.008, \mathrm{OR}=2.2$ (1.2-4.2). Both sexes exhibited similar allele associations with $\mathrm{Ml}$, with $\varepsilon 4$ tending to be positively associated with $\mathrm{Ml}$ in men $(\mathrm{OR}=1.8, \mathrm{p}=0.04)$ and women $(\mathrm{OR}=1.9, \mathrm{p}=0.10)$, and $\varepsilon 2$ tending toward a negative 
Table 1 Characteristics of stroke, control, and MI subjects.

\begin{tabular}{|c|c|c|c|c|c|}
\hline & $\begin{array}{l}\text { Stroke } \\
(n=246)\end{array}$ & $\mathrm{p}$ & $\begin{array}{l}\text { Controls } \\
(n=336)\end{array}$ & $p$ & $\begin{array}{l}\mathrm{MI} \\
(\mathrm{n}=234)\end{array}$ \\
\hline Age, years & $70.7 \pm 12$ & 0.24 & $71.0 \pm 5.9$ & $<0.001$ & $58.3 \pm 9.6$ \\
\hline Men, \% & 54.5 & 0.03 & 45.2 & $<0.001$ & 81.6 \\
\hline $\mathrm{SBP}, \mathrm{mm} \mathrm{Hg}$ & $166 \pm 28$ & $<0.001$ & $142 \pm 20$ & & - \\
\hline $\mathrm{DBP}, \mathrm{mm} \mathrm{Hg}$ & $85.4 \pm 19$ & $<0.001$ & $71.9 \pm 13$ & & - \\
\hline Hypertension, \% & 65.9 & 0.20 & 60.2 & & - \\
\hline Diabetes, \% & 30.5 & $<0.001$ & 17.5 & 0.99 & 17.4 \\
\hline Former smoker, $\%^{a}$ & 21.1 & 0.61 & 26.3 & $<0.001$ & 43.5 \\
\hline Current smoker, $\%^{\mathrm{a}}$ & 22.7 & $<0.001$ & 11.3 & $<0.001$ & 28.7 \\
\hline $\mathrm{TC}, \mathrm{mmol} / \mathrm{L}$ & $5.58 \pm 1.14$ & 0.32 & $5.47 \pm 0.91$ & & - \\
\hline $\mathrm{HDL}, \mathrm{mmol} / \mathrm{L}$ & $1.35 \pm 0.36$ & 0.32 & $1.31 \pm 0.34$ & & - \\
\hline LDL, mmol/L & $3.48 \pm 1.00$ & 0.96 & $3.48 \pm 0.81$ & & - \\
\hline $\mathrm{TG}, \mathrm{mmol} / \mathrm{L}^{\mathrm{b}}$ & $1.55(1.44-1.67)$ & $<0.001$ & $1.30(1.22-1.39)$ & & - \\
\hline
\end{tabular}

Values are mean $\pm S D$, number of subjects, or percentage. - , no data. ${ }^{a} p$ for $\chi^{2}$ comparison with never smokers; ${ }^{b}$ geometric mean of TG $(95 \%$ confidence interval).

association with $\mathrm{MI}$ in men (OR=0.3, $\mathrm{p}=0.00002$ ) and women $(O R=0.4, p=0.11)$. Excluding $\varepsilon 2 / \varepsilon 4$ carriers, lipid values or mean age did not differ between carriers of $\varepsilon 3 / \varepsilon 3$ and either $\varepsilon 2$ or $\varepsilon 4$ in either stroke or control subjects, while in $\mathrm{MI}$ patients carrying $\varepsilon 4 \mathrm{com}-$ pared to $\varepsilon 3 / \varepsilon 3$, mean age was younger (55.2 vs. 59.0 years, $\mathrm{p}=0.01$ ).

$L P L$ genotype and allele distributions did not differ between patients and controls (Table 3). However, opposite associations between $X$ alleles and disease were observed in men vs. women, smokers vs. nonsmokers, and $A P O E \varepsilon 3 / \varepsilon 3$ carriers vs. non-carriers (Table 3): men, $\mathrm{OR}=0.75$ (95\% Cl: 0.49-1.2), $\mathrm{p}=0.18$; women, $\mathrm{OR}=1.7$ (1.0-3.0), $\mathrm{p}=0.04$; current smokers, $\mathrm{OR}=0.84(0.30-2.7), \mathrm{p}=0.72$; never smoked, $\mathrm{OR}=1.3$ (0.84-2.2), $\mathrm{p}=0.20 ; A P O E \varepsilon 3 / \varepsilon 3, \mathrm{OR}=0.81(0.54-1.2)$, $\mathrm{p}=0.30 ; A P O E$ non $-\varepsilon 3 / \varepsilon 3, \mathrm{OR}=2.2(1.1-4.3), \mathrm{p}=0.01$.

To compare the effects of smoking and LPL $X$ alleles on vascular disease, odds ratios for disease were calculated relative to $L P L S S$ never smokers: $X+$ never smokers, $O R=1.3(0.84-2.2), \mathrm{p}=0.20$; $S S$ current smokers, $\mathrm{OR}=3.5(2.6-4.9), \mathrm{p}<0.00001 ; X+$ cur- rent smokers, $O R=3.0(1.1-9.3), p=0.02$. Since most smokers were men, subjects were re-analyzed after segregating by smoking and sex. Among never smokers, the opposite odds ratios of men and women remained nearly the same, suggesting that the sex effect is not secondary to a smoking effect. There were too few current smokers to obtain reliable odds ratios after stratifying by sex and genotype. Although $\mathrm{MI}$ and stroke were associated with different $A P O E$ genotypes, both diseases tended to associate with the combination of $L P L X+$ and $A P O E$ non $-\varepsilon 3 / \varepsilon 3$ genotypes.

Several parameters differed between carriers of $L P L$ $X+$ and $S S$ (Table 4). Among stroke patients, lipid levels did not differ significantly between $X+$ and $S S$ carriers.

\section{Logistic regression}

In various subject groups, multiple logistic regression identified different variables associated with disease. These variables, listed in the legend to Table 5, were

Table 2 Distribution of $A P O E$ genotypes and alleles in stroke and MI patients and controls.

\begin{tabular}{|c|c|c|c|}
\hline $\begin{array}{l}A P O E \\
\text { genotype }\end{array}$ & $\begin{array}{l}\text { Controls } \\
(n=311)\end{array}$ & $\begin{array}{l}\text { Stroke } \\
(n=243)\end{array}$ & $\begin{array}{l}\mathrm{MI} \\
(\mathrm{n}=231)\end{array}$ \\
\hline$\varepsilon 2 / \varepsilon 2$ & $2(0.6 \%)$ & $7(2.9 \%)$ & $0(0.0 \%)$ \\
\hline$\varepsilon 2 / \varepsilon 3$ & $60(19.3 \%)$ & $39(16.0 \%)$ & $13(5.6 \%)$ \\
\hline$\varepsilon 2 / \varepsilon 4$ & $6(1.9 \%)$ & $6(2.5 \%)$ & $4(1.7 \%)$ \\
\hline$\varepsilon 3 / \varepsilon 3$ & $203(65.3 \%)$ & $155(63.8 \%)$ & $164(71.0 \%)$ \\
\hline$\varepsilon 3 / \varepsilon 4$ & $39(12.5 \%)$ & $32(13.2 \%)$ & $46(19.9 \%)$ \\
\hline \multirow[t]{4}{*}{$\varepsilon 4 / \varepsilon 4$} & $1(0.3 \%)$ & $4(1.6 \%)$ & $4(1.7 \%)$ \\
\hline & & $\varepsilon 2 / \varepsilon 2+\varepsilon 4 / \varepsilon 4: \mathrm{p}=0.008$ & $\varepsilon 3 / \varepsilon 4+\varepsilon 4 / \varepsilon 4: \mathrm{p}=0.007$ \\
\hline & & $\mathrm{OR}=4.9(95 \% \mathrm{Cl} 1.3-27)$ & $\mathrm{OR}=1.9(95 \% \mathrm{Cl} 1.2-3.0)$ \\
\hline & & & $\begin{array}{l}\varepsilon 2 / \varepsilon 3+\varepsilon 2 / \varepsilon 2: \mathrm{p}=0.000002 \\
\mathrm{OR}=0.24(95 \% \mathrm{Cl} 0.1-0.5)\end{array}$ \\
\hline \multirow[t]{2}{*}{ Allele } & Controls & Stroke & $\mathrm{MI}$ \\
\hline & $(n=622)$ & $(n=486)$ & $(n=462)$ \\
\hline$\varepsilon 2$ & $70(11.3 \%)$ & $59(12.1 \%)$ & $17(3.7 \%)$ \\
\hline$\varepsilon 3$ & $505(81.2 \%)$ & $381(78.4 \%)$ & $387(83.8 \%)$ \\
\hline \multirow[t]{5}{*}{$\varepsilon 4$} & $47(7.6 \%)$ & $46(9.5 \%)$ & $58(12.6 \%)$ \\
\hline & & & $\varepsilon 4: \mathrm{p}=0.006$ \\
\hline & & & $\mathrm{OR}=1.8(95 \% \mathrm{Cl} 1.2-2.7)$ \\
\hline & & & $\varepsilon 2: \mathrm{p}=0.000006$ \\
\hline & & & $\mathrm{OR}=0.30(95 \% \mathrm{Cl} 0.2-0.5)$ \\
\hline
\end{tabular}


Table 3 Distribution of LPL S447X genotypes and alleles: p-values and ORs (95\% Cls) on the left are for $X+$ genotypes, and on the right are for $X$ alleles.

\begin{tabular}{|c|c|c|c|c|c|c|}
\hline & \multirow[t]{2}{*}{$\mathrm{n}$} & \multicolumn{3}{|c|}{ Genotype } & \multicolumn{2}{|l|}{ Allele } \\
\hline & & $x X$ & $X S$ & SS & $x$ & $S$ \\
\hline Stroke patients & 243 & $8(3.3 \%)$ & $44(18.1 \%)$ & $191(78.6 \%)$ & $60(12.3 \%)$ & $426(87.7 \%)$ \\
\hline MI patients & 231 & $0(0.0 \%)$ & $51(22.1 \%)$ & $180(77.9 \%)$ & $51(11.0 \%)$ & $411(89.0 \%)$ \\
\hline All patients & 474 & $8(1.7 \%)$ & $95(20.0 \%)$ & $371(78.3 \%)$ & $111(11.7 \%)$ & $837(88.3 \%)$ \\
\hline \multirow[t]{2}{*}{ Controls } & 313 & $1(0.3 \%)$ & $64(20.4 \%)$ & $248(79.2 \%)$ & $66(10.5 \%)$ & $560(89.5 \%)$ \\
\hline & & \multicolumn{3}{|c|}{$\mathrm{OR}_{\mathrm{All}}=1.1(0.7-1.5), \mathrm{p}=0.75$} & \multicolumn{2}{|c|}{$\mathrm{OR}_{\mathrm{AII}}=1.1(0.8-1.6), \mathrm{p}=0.47$} \\
\hline Female, all patients & 153 & $4(2.6 \%)$ & $29(19.0 \%)$ & $120(78.4 \%)$ & $37(12.1 \%)$ & $269(87.9 \%)$ \\
\hline Female, controls & 176 & $\begin{array}{l}0(0.0 \%) \\
O R=1.6\end{array}$ & $\begin{array}{r}26(14.8 \%) \\
-29) \quad p=0.1\end{array}$ & $150(85.2 \%)$ & $\begin{array}{l}26(7.4 \%) \\
O R=1.7(1.0\end{array}$ & $\begin{array}{l}326(92.6 \%) \\
p=0.04\end{array}$ \\
\hline Male, all patients & 320 & $4(1.3 \%)$ & $65(20.3 \%)$ & $251(78.4 \%)$ & $73(11.4 \%)$ & $567(88.6 \%)$ \\
\hline \multirow[t]{2}{*}{ Male, controls } & 137 & $1(0.7 \%)$ & $38(27.7 \%)$ & 98 (71.5\%) & $40(14.6 \%)$ & $234(75.4 \%)$ \\
\hline & & \multicolumn{3}{|c|}{$\mathrm{OR}=0.69(0.43-1.1), \mathrm{p}=0.11$} & \multicolumn{2}{|c|}{$\mathrm{OR}=0.75(0.49-1.2), \mathrm{p}=0.18$} \\
\hline Current smoker, all patients & 117 & $0(0.0 \%)$ & $17(14.5 \%)$ & $100(85.5 \%)$ & $17(7.3 \%)$ & $217(92.7 \%)$ \\
\hline \multirow[t]{2}{*}{ Current smoker, controls } & 35 & $0(0.0 \%)$ & $6(17.1 \%)$ & $29(82.9 \%)$ & $6(8.6 \%)$ & $64(91.4 \%)$ \\
\hline & & \multicolumn{3}{|c|}{$\mathrm{OR}=0.82(0.28-2.8), \mathrm{p}=0.71$} & \multicolumn{2}{|c|}{$\mathrm{OR}=0.84(0.30-2.7), \mathrm{p}=0.72$} \\
\hline Ever smoker, all patients & 262 & $2(0.8 \%)$ & $50(19.0 \%)$ & $210(80.2 \%)$ & $54(10.3 \%)$ & $470(89.7 \%)$ \\
\hline \multirow[t]{2}{*}{ Ever smoker, controls } & 114 & $1(0.9 \%)$ & $25(21.9 \%)$ & 88 (77.2\%) & $27(11.8 \%)$ & $201(88.2 \%)$ \\
\hline & & \multicolumn{3}{|c|}{$\mathrm{OR}=0.84(0.48-1.5), \mathrm{p}=0.52$} & \multicolumn{2}{|c|}{$\mathrm{OR}=0.86(0.51-1.5), \mathrm{p}=0.53$} \\
\hline Never smoked, all patients & 196 & $5(2.6 \%)$ & $40(20.4 \%)$ & $151(77.0 \%)$ & $50(12.8 \%)$ & $342(87.2 \%)$ \\
\hline \multirow[t]{2}{*}{ Never smoked, controls } & 198 & $0(0.0 \%)$ & $39(19.7 \%)$ & $159(80.3 \%)$ & $39(9.8 \%)$ & $357(90.2 \%)$ \\
\hline & & \multicolumn{3}{|c|}{$\mathrm{OR}=1.2(0.7-2.0), \mathrm{p}=0.43$} & \multicolumn{2}{|c|}{$\mathrm{OR}=1.3(0.84-2.2), \mathrm{p}=0.20$} \\
\hline$A P O E \varepsilon 3 / \varepsilon 3$, all patients & 318 & $5(1.6 \%)$ & $58(18.2 \%)$ & $255(80.2 \%)$ & $68(10.7 \%)$ & $568(89.3 \%)$ \\
\hline \multirow[t]{2}{*}{$A P O E \varepsilon 3 / \varepsilon 3$, controls } & 199 & $1(0.5 \%)$ & $49(24.6 \%)$ & $149(74.9 \%)$ & $51(12.8 \%)$ & $347(87.2 \%)$ \\
\hline & & \multicolumn{3}{|c|}{$\mathrm{OR}=0.74(0.47-1.2), \mathrm{p}=0.15$} & \multicolumn{2}{|c|}{$\mathrm{OR}=0.81(0.54-1.2), \mathrm{p}=0.30$} \\
\hline$A P O E$ non- $\varepsilon 3 / \varepsilon 3$, all patients & 154 & $3(1.9 \%)$ & $36(23.4 \%)$ & $115(74.7 \%)$ & $42(13.6 \%)$ & $266(86.4 \%)$ \\
\hline \multirow[t]{2}{*}{$A P O E$ non $-\varepsilon 3 / \varepsilon 3$, controls } & 104 & $0(0.0 \%)$ & $14(13.5 \%)$ & $90(86.5 \%)$ & $14(6.7 \%)$ & $194(93.3 \%)$ \\
\hline & & \multicolumn{3}{|c|}{$\mathrm{OR}=2.2(1.1-4.6), \mathrm{p}=0.02$} & \multicolumn{2}{|c|}{$\mathrm{OR}=2.2(1.1-4.3), \mathrm{p}=0.01$} \\
\hline
\end{tabular}

used to adjust the association of genotypes with disease (Table 5). The association of APOE genotypes with $\mathrm{MI}$ remained highly significant after adjustment. The odds ratio for association of APOE genotypes with stroke was even greater than that for $\mathrm{MI}$, although this association lost its significance after adjustment, perhaps because of the small number of subjects with $\varepsilon 2 / \varepsilon 2$ or $\varepsilon 4 / \varepsilon 4$. The associations of $L P L$ $X+$ genotypes with vascular disease in women, never smokers, and $A P O E$ non- $\varepsilon 3 / \varepsilon 3$ genotypes were somewhat less significant after adjustment, although the association among $A P O E$ non- $\varepsilon 3 / \varepsilon 3$ genotypes remained significant.

Interactions of genotypes with other factors were included in the multivariate models of genotypes and clinical characteristics for stroke and for MI. No sig- nificant interactions were associated with MI. LPL genotype interacted with never smoking and with hypertension to associate with stroke.

\section{Meta-analysis}

We combined results of published case-control studies of ischemic heart disease or stroke to attempt to confirm the tendencies we observed toward opposite associations between $L P L$ alleles and disease in men vs. women and in smokers vs. non-smokers. In men, $X$ alleles were decreased in disease: $\mathrm{OR}=0.83(95 \%$ $\mathrm{Cl} 0.73-0.93$ ), $\mathrm{p}=0.002$ (Figure 1). $X X$ genotypes displayed a non-significant tendency toward a greater reduction: $\mathrm{OR}=0.67(0.41-1.09, \mathrm{p}=0.10)$. However, in

Table 4 Comparison of various measures in LPL X+ vs. SS carriers in subsets of subjects.

\begin{tabular}{|c|c|c|c|c|c|}
\hline Test & Subjects & Measure & $L P L X+$ & $\mathrm{p}$ & LPL SS \\
\hline a & $\mathrm{MI}$ & Age, years & $61.1 \pm 9.2$ & 0.04 & $57.2 \pm 9.1$ \\
\hline b & Stroke & NIH Stroke Scale & $5.3 \pm 3.9$ & 0.02 & $7.7 \pm 6.4$ \\
\hline c & Control & $\mathrm{HDL}, \mathrm{mmol} / \mathrm{L}$ & $1.41 \pm 0.29$ & 0.02 & $1.29 \pm 0.36$ \\
\hline d & Control & LDL, mmol/L & $3.69 \pm 0.81$ & 0.05 & $3.43 \pm 0.80$ \\
\hline e & Control & $\mathrm{TG}, \mathrm{mmol} / \mathrm{L}$ & $1.09(0.96-1.22)$ & 0.01 & $1.35(1.25-1.46)$ \\
\hline$f$ & Control: men & $\mathrm{TG}, \mathrm{mmol} / \mathrm{L}$ & $1.10(0.93-1.30)$ & 0.13 & $1.40(1.21-1.63)$ \\
\hline g & Control: women & $\mathrm{TG}, \mathrm{mmol} / \mathrm{L}$ & $1.06(0.88-1.28)$ & 0.03 & $1.31(1.20-1.44)$ \\
\hline h & Control: $A P O E \varepsilon 3 / \varepsilon 3$ & $\mathrm{TG}, \mathrm{mmol} / \mathrm{L}$ & $1.07(0.93-1.24)$ & 0.05 & $1.32(1.19-1.47)$ \\
\hline i & Control: $A P O E$ non- $\varepsilon 3 / \varepsilon 3$ & $\mathrm{TG}, \mathrm{mmol} / \mathrm{L}$ & $1.14(0.87-1.49)$ & 0.10 & $1.40(1.22-1.60)$ \\
\hline
\end{tabular}

Mean \pm SD are shown for rows (a)-(d), and geometric mean (95\% confidence interval) are shown for rows (e)-(i). p-Values were determined by ANCOVA after adjusting for the following factors: a) sex, diabetes, hypertension, and smoking, coded as 1 for never smoker, 2 for ex-smoker, and 3 for current smoker; b) age, sex, diabetes, hypertension, SBP, DBP, and smoking coded as above; c) age, sex, diabetes, hypertension, SBP, DBP, TC, LDL, and smoking coded as above; d) age, sex, diabetes, hypertension, SBP, DBP, HDL, $\log _{10} \mathrm{TG}$, and smoking coded as above; e-i) age, sex, diabetes, hypertension, SBP, DBP, TC, $\mathrm{LDL}$, and smoking coded as above. 
Table 5 Logistic regression analysis.

\begin{tabular}{|c|c|c|c|}
\hline Genotype & Subjects & $\begin{array}{l}\text { Adjusted OR }(95 \% \mathrm{Cl}) \\
\text { for disease }\end{array}$ & $p$ \\
\hline a) $A P O E$ & Stroke and control & $3.0(0.6-16)$ for stroke & 0.19 \\
\hline b) $A P O E$ & MI and control & $2.4(1.7-3.6)$ for $\mathrm{MI}$ & 0.000005 \\
\hline c) $L P L X+$ & Women & $1.4(0.7-2.5)$ for stroke or $\mathrm{MI}$ & 0.3 \\
\hline d) $L P L X+$ & Never smokers & $1.1(0.6-1.8)$ for stroke or $\mathrm{MI}$ & 0.8 \\
\hline e) $L P L X+$ & $A P O E$ non- $\varepsilon 3 / \varepsilon 3$ & $2.2(1.1-4.4)$ for stroke or $\mathrm{Ml}$ & 0.03 \\
\hline f) Never smoker $\times L P L X+$ & Stroke and control & $3.2(1.3-7.9)$ & 0.02 \\
\hline Hypertension $\times L P L X+$ & & $0.42(0.17-1.0)$ & 0.05 \\
\hline
\end{tabular}

In subsets of subjects, multiple logistic regression was used to find factors associated with disease at $p<0.1$. These factors were then used to adjust the associations of genotypes with diseases. The following factors were used: a) age, SBP, DBP, diabetes, current smoking, and $\log _{10} \mathrm{TG}$, for $A P O E \varepsilon 2 / \varepsilon 2+\varepsilon 4 / \varepsilon 4$; b) sex, current smoking, and former smoking, for $A P O E$ coded as -1 for $\varepsilon 2 / \varepsilon 2$ or $\varepsilon 2 / \varepsilon 3,0$ for $\varepsilon 2 / \varepsilon 4$ or $\varepsilon 3 / \varepsilon 3$, and 1 for $\varepsilon 4 / \varepsilon 4$ or $\varepsilon 3 / \varepsilon 4$; c) diabetes, current smoking, and former smoking; d) sex and diabetes; e) sex and current smoking; f) age, SBP, DBP, diabetes, current smoking, and $\log _{10} \mathrm{TG}$.

women, neither $X$ alleles $(p=0.52)$ nor $X X$ genotypes $(p=0.63)$ showed a negative association with disease. Since most studies did not present genotype results separately by sex, we attempted to gain further information by using regression of weighted $X$ allele odds ratios vs. the proportion of males for all studies, including this report, with studies divided into independent male and female parts when possible. The slope of the regression was -0.16 (OR/proportion male), $p=0.15$.

Since no papers presented genotype results separately by smoking status, we used regression analysis to compare weighted $X$ allele odds ratios against proportion of current smokers (Figure 2) $(4,28-32)$. The slope of the regression was -0.88 (OR/proportion smokers), $p=0.02$. Using the regression line, the predicted odds ratio was 0.4 for current smokers and 1.3 for never smokers.

\section{Discussion}

Our findings are consistent with reports of a positive association of the APOE exon $4 \varepsilon 4$ allele with $\mathrm{MI}$, but only some studies reported a significant negative association between $\mathrm{Ml}$ and $\varepsilon 2(9,15)$. ApoE, as a constituent of very low-density lipoprotein particles, binds LDL receptor (LDLR), LDLR-related protein (LRP), and other receptors, thus aiding the catabolism of TG-rich lipoproteins and cholesterol homeostasis $(8,9)$. ApoE E2, the protein isoform coded by the $\varepsilon 2$ allele, binds LDLR poorly, which may increase the number of LDLRs, thereby lowering cholesterol levels $(8,10)$. The E4 form exhibits enhanced transfer from HDL to TG-rich lipoproteins, accelerating hepatic remnant clearance by apoE receptors and decreasing LDLR numbers, thereby increasing cholesterol levels $(8,10)$.
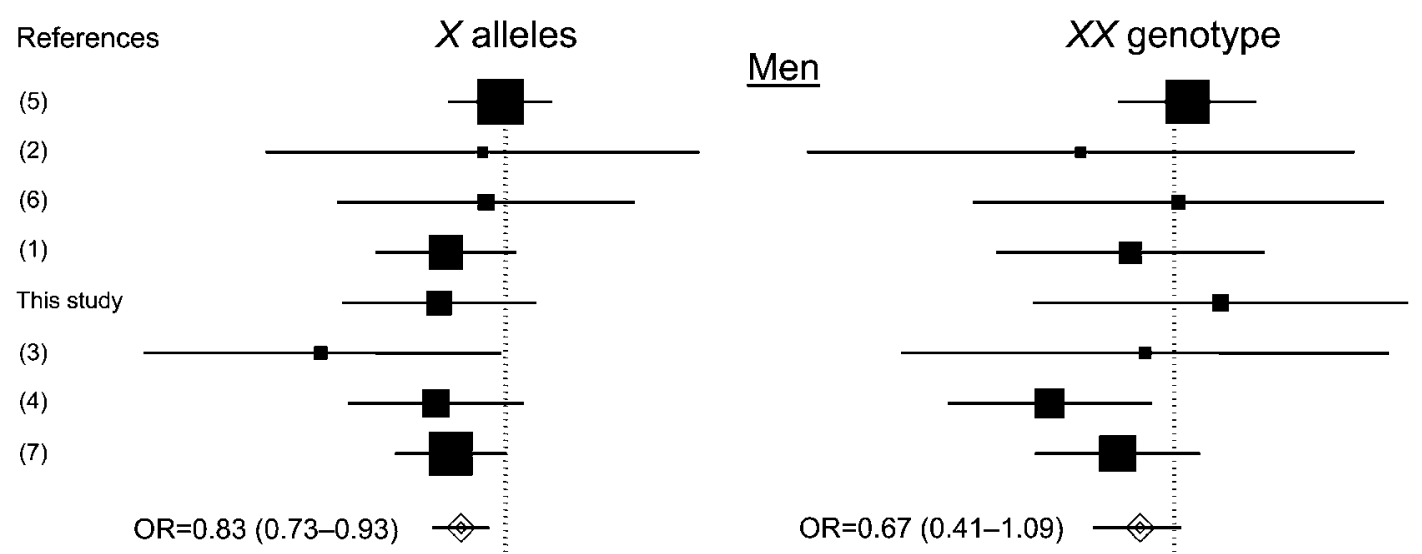

(5)

This study

(3)

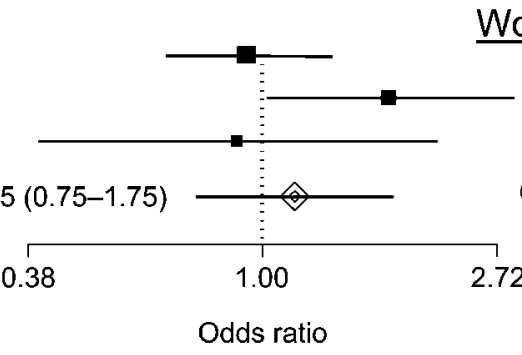

Women

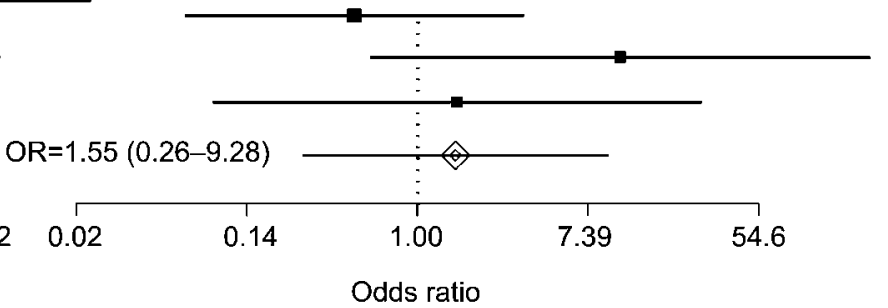

Figure 1 Meta-analysis of LPL. Meta-analysis of the association of LPL alleles and genotypes with vascular disease in men (top) and women (bottom). 


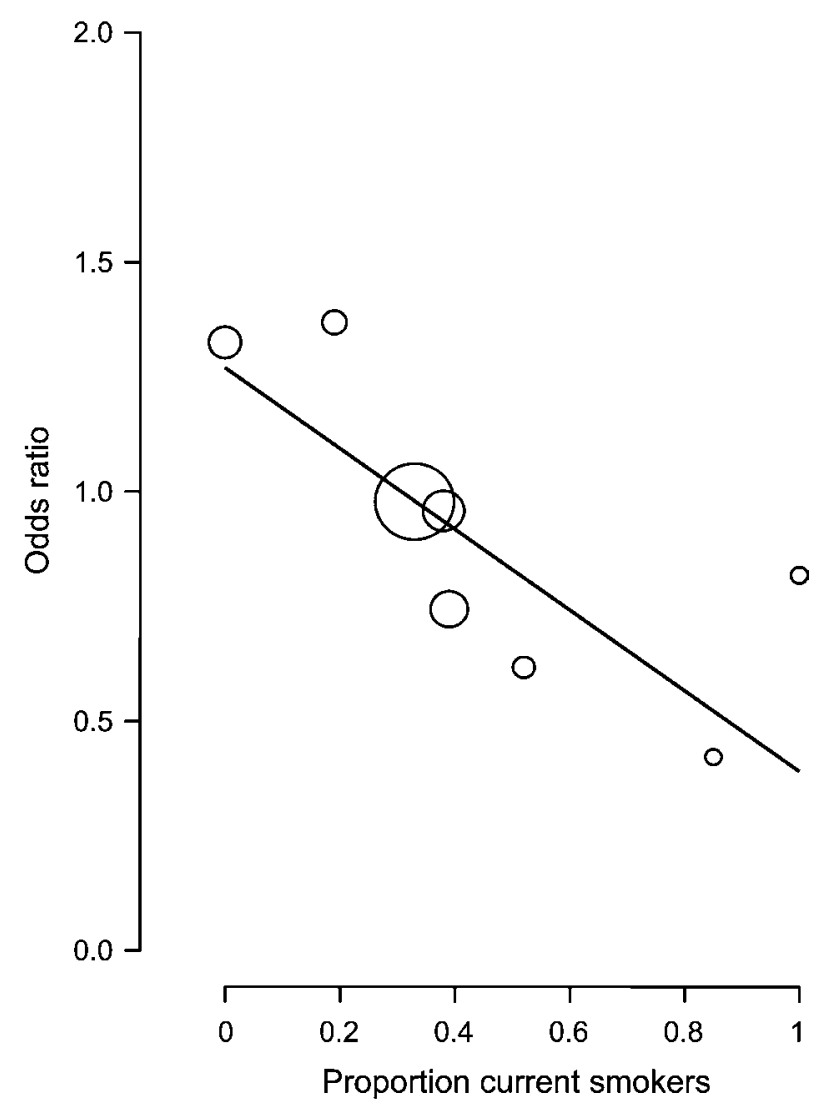

Figure 2 Regression of smoking and $L P L$. Regression analysis for association of $L P L X$ alleles with vascular disease by proportion of current smokers among patients in published studies $(4,28-32)$. Circle area is proportional to the number of subjects in the study. Regression: slope $-0.88, p=0.02$.

The greater stroke frequency we observed not only for $\varepsilon 4$, but also for $\varepsilon 2$ homozygotes has not been generally reported, perhaps because of the rarity of the $\varepsilon 2 / \varepsilon 2$ genotype (11). One possibility is that our observation is due to chance, since the p-value we observed (0.008) would not meet a Bonferroni-corrected significance level of 0.0016 ( 0.05 divided by 31, or the number of possible ways to dichotomize the six APOE genotypes). Meta-analysis of similar studies might provide the additional statistical power needed to confirm or refute this observation. If confirmed, a possible physiological explanation could be that the reduced receptor binding of E2 can increase circulating chylomicron remnant levels, especially after a meal (10), which might for unknown reasons increase the risk of stroke more than the risk of Ml. Alternatively, the contrasting associations of $\varepsilon 2$ with $\mathrm{Ml}$ and stroke might reflect the younger age of $\mathrm{MI}$ than stroke patients, rather than a difference in etiologies. In a study comparing young and old CHD patients, $\varepsilon 4$ was increased in young patients, while $\varepsilon 2$ was increased in old patients (12).

Among subjects with hypertension, we found an increased risk of stroke or $\mathrm{Ml}$ associated with the $\varepsilon 4$ allele. It may be speculated that the combination of hypertension and $\varepsilon 4$ has a multiplicative effect, because these two risk factors might act through different pathogenic mechanisms.
The current results associated $L P L X+$ carriers with several factors that suggested protection from vascular disease: lower TG, delayed age of MI, and less severe strokes. In meta-analysis, $X$ alleles were indeed significantly negatively associated with vascular disease, although our own data showed associations of $X$ alleles with vascular disease only in subsets of subjects. In a meta-analysis that expanded on one performed 3 years ago (5), $X$ alleles were significantly negatively associated with stroke or cardiovascular disease in men, but not in women. It is possible that our result for women is an outlier that appears to eliminate the protective effect of $X$ alleles. However, if the sexual divergence is confirmed in further studies, then our failure, and that of some other studies, to see a significant effect of $X$ in all subjects (combined sexes) may be due to a small sample size or to the mix of subjects. For example, a largely male study population may yield a significant effect, while studies with a high proportion of women may not.

In multiple logistic regression analysis, we observed interactive associations of LPL $X+$ genotypes with stroke that may give insight into the role of this polymorphism in vascular disease. $X+$ genotypes in conjunction with hypertension appeared to be protective, but $X+$ in conjunction with never smoking appeared to be harmful. The effects of these two interactions could be interpreted in a consistent way: $X+$ protecting those at high risk of ischemic vascular disease, such as smokers or those with hypertension or other risk factors, and conversely harming those at low risk. The apparent protective effect of $X+$ in men but not women might reflect the fact that men generally have greater risk of ischemic vascular disease.

Although $X+$ genotypes showed decreased TG levels in both female and male controls, the lack of a protective effect against vascular disease in women might be due to the lower TG levels in women than men, in both genotypes (19), with reduced benefit to women from any further TG-lowering by $X+$ genotypes. An alternative explanation could be that the $X$ allele raises LPL activity, and that the net effect of $X$ on vascular risk is a balance between the resulting reduction in circulating TG (good) and the accelerated atherosclerosis caused by increased LPL expression by macrophages in plaques (bad) (16). Estrogen increases LPL expression by macrophages, thus perhaps pushing the balance relatively more toward the harmful end in women (33). However, estrogen also increases HDL levels (34), which might counter this harmful effect.

This is the first report of an association of vascular disease with an interaction of smoking and LPL S447X genotype. Although the type of regression analysis that revealed this interaction may be less powerful than meta-analysis (as shown, for example, by the lack of significance in regression of sex vs. odds ratio of disease with $X$, despite the significant effect revealed by the corresponding meta-analysis), the fact that regression, despite its weakness, did reveal a significant interaction of smoking with LPL S447X genotype suggests that this effect may be strong. In 
general, regression may be a useful tool for examination of published studies for potential association of disease with a factor that was not stratified.

The association with vascular disease increased in the order $S S$ non-smoker $<X+$ non-smoker $<X+$ smoker $<S S$ smoker. A similar interaction order was reported for the $L P L$ D9N polymorphism: $N+$ nonsmoker $\angle D D$ non-smoker $\angle D D$ smoker $<N+$ smoker (14). N9 and S447 reduce LPL activity and raise TG levels (14, 17-19). Smoking decreases LPL activity and raises TG (21), perhaps lowering risk by reducing endothelial-located, pro-atherogenic LPL and raising risk by reducing non-endothelial, anti-atherogenic LPL (16). Thus, polymorphisms may affect risk via the latter effect in smokers and the former in non-smokers, resulting in opposite effects of genotypes in smokers vs. non-smokers. N9 LPL binds more LDL, and thus may recruit oxidized LDL and monocytes to smokinginduced endothelial lesions, exacerbating atherosclerosis in smokers, although why N9 reduces risk in non-smokers remains unexplained $(14,16)$. To exclude the possibility that sex confounds these smoking interactions (because most smokers are men), subjects can be analyzed separately by smoking and sex, but our study had too few current smokers to do so reliably.

This is the first report of an association between vascular disease and an interaction of $A P O E$ exon 4 and $L P L S 447 X$ genotypes. The greater odds ratio with the $A P O E$ non- $\varepsilon 3 / \varepsilon 3$ and $L P L X+$ combination did not correspond to a greater TG level in ours or a previous study (20). It is not clear why both $A P O E \varepsilon 2$ and $\varepsilon 4$ alleles would induce similar effects, but perhaps the same destination is reached via different routes. ApoE protein levels and LPL activity are higher in $\varepsilon 2$ carriers, and LDL-C is raised in $\varepsilon 4$ carriers $(8,18$, 20). The combination of either $\varepsilon 2$ or $\varepsilon 4$ with the increased LPL activity in $X$ carriers $(17,18,20)$ might bring more oxidized LDL and macrophages into atherosclerotic plaques (16). LPL from macrophages can be atherogenic, perhaps by binding lipoproteins to sites of endothelial damage, converting TG-rich lipoproteins into remnants and creating toxic products of lipolysis, or affecting macrophage function $(16,35)$. However, apoE expression protected against atherosclerosis induced by macrophage-specific LPL in mice (22), and thus the effect of $A P O E \varepsilon 2$ in our study might not be due to increased apoE protein levels, but rather due to another factor, such as delayed remnant clearance (15).

This study has limitations. Lack of body mass index or lipoprotein(a) data precluded adjusting for these factors in multivariate logistic regression. Multiple comparisons may produce false-positive associations. Rather than reducing the chance of their occurrence by Bonferroni correction of significance levels, we chose to present the data and let readers interpret the results with appropriate caution, allowing new associations to be uncovered that may otherwise remain hidden. However, it will be necessary to confirm or refute these findings in independent populations in studies performed by other investigators.
Limitations for the MI portion of the study include lack of some data for MI patients, and a control population older than the Ml patients. This lack of age matching is a possible source of bias. Another limitation is that the study design is case-control, which may be prone to bias in subject selection and matching. On the other hand, case-control studies provide good statistical power compared to prospective studies of similar size. Ideally, findings of case-control studies will be confirmed or refuted by prospective studies.

Because S447X is the most common LPL coding polymorphism, the effects of interactions with smoking or the apoE exon 4 polymorphism on population risk would be great, and should spur authors of previous studies of this polymorphism and vascular disease to stratify their results by smoking status, sex, and $A P O E$ genotype to confirm or refute our findings. However, when stratified data are absent, regression can be attempted as an alternative method of combining results of multiple studies to discover interactions.

\section{Acknowledgements}

Supported by Earmarked Research Grant CUHK 4069/02M from the Hong Kong Research Grants Council.

\section{References}

1. Galton DJ, Mattu R, Needham EW, Cavanna J. Identification of putative beneficial mutations for lipid transport. $Z$ Gastroenterol 1996;34(Suppl 3):56-8.

2. Peacock RE, Hamsten A, Nilsson-Ehle P, Humphries SE. Associations between lipoprotein lipase gene polymorphisms and plasma correlations of lipids, lipoproteins and lipase activities in young myocardial infarction survivors and age-matched healthy individuals from Sweden. Atherosclerosis 1992;97:171-85.

3. Gagne SE, Larson MG, Pimstone SN, Schaefer EJ, Kastelein JJ, Wilson PW, et al. A common truncation variant of lipoprotein lipase (Ser447X) confers protection against coronary heart disease: the Framingham Offspring Study. Clin Genet 1999;55:450-4.

4. Reymer PW, Gagne E, Groenemeyer BE, Zhang H, Forsyth I, Jansen $H$, et al. A lipoprotein lipase mutation (Asn291Ser) is associated with reduced HDL cholesterol levels in premature atherosclerosis. Nat Genet 1995; 10:28-34.

5. Wittrup $\mathrm{HH}$, Nordestgaard BG, Steffensen R, Jensen G, Tybjaerg-Hansen A. Effect of gender on phenotypic expression of the S447X mutation in LPL: the Copenhagen City Heart Study. Atherosclerosis 2002;165:119-26.

6. Mattu RK, Needham EW, Morgan R, Rees A, Hackshaw AK, Stocks J, et al. DNA variants at the LPL gene locus associate with angiographically defined severity of atherosclerosis and serum lipoprotein levels in a Welsh population. Arterioscler Thromb 1994; 1 4:1090-7.

7. Jemaa R, Fumeron F, Poirier O, Lecerf L, Evans A, Arveiler $D$, et al. Lipoprotein lipase gene polymorphisms: associations with myocardial infarction and lipoprotein levels, the ECTIM study. Etude Cas Temoin sur I'Infarctus du Myocarde. J Lipid Res 1995;36:2141-6.

8. Davignon J, Gregg RE, Sing CF. Apolipoprotein E polymorphism and atherosclerosis. Arteriosclerosis 1988; 8:1-21. 
9. Kolovou G, Daskalova D, Mikhailidis DP. Apolipoprotein E polymorphism and atherosclerosis. Angiology 2003; 54:59-71.

10. Lahoz C, Schaefer EJ, Cupples LA, Wilson PW, Levy D, Osgood D, et al. Apolipoprotein E genotype and cardiovascular disease in the Framingham Heart Study. Atherosclerosis 2001;154:529-37.

11. McCarron MO, Delong D, Alberts MJ. APOE genotype as a risk factor for ischemic cerebrovascular disease: a meta-analysis. Neurology 1999;53:1308-11.

12. Nassar BA, Dunn J, Title LM, O'Neill BJ, Kirkland SA, Zayed $E$, et al. Relation of genetic polymorphisms of apolipoprotein $E$, angiotensin converting enzyme, apolipoprotein B-100, and glycoprotein IIla and early-onset coronary heart disease. Clin Biochem 1999;32:275-82.

13. Shimo-Nakanishi $Y$, Urabe T, Hattori N, Watanabe $Y$, Nagao T, Yokochi M, et al. Polymorphism of the lipoprotein lipase gene and risk of atherothrombotic cerebral infarction in the Japanese. Stroke 2001;32:1481-6.

14. Talmud PJ, Stephens JW. Lipoprotein lipase gene variants and the effect of environmental factors on cardiovascular disease risk. Diabetes Obes Metab 2004;6:1-7.

15. Wilson PW, Schaefer EJ, Larson MG, Ordovas JM. Apolipoprotein $\mathrm{E}$ alleles and risk of coronary disease. A meta-analysis. Arterioscler Thromb Vasc Biol 1996; 16:1250-5.

16. Clee SM, Bissada N, Miao F, Miao L, Marais AD, Henderson $\mathrm{HE}$, et al. Plasma and vessel wall lipoprotein lipase have different roles in atherosclerosis. J Lipid Res 2000;41:521-31.

17. Groenemeijer BE, Hallman MD, Reymer PW, Gagne E, Kuivenhoven JA, Bruin T, et al. Genetic variant showing a positive interaction with beta-blocking agents with a beneficial influence on lipoprotein lipase activity, HDL cholesterol, and triglyceride levels in coronary artery disease patients. The Ser447-stop substitution in the lipoprotein lipase gene. REGRESS Study Group. Circulation 1997:95:2628-35.

18. Henderson HE, Kastelein JJ, Zwinderman AH, Gagne E, Jukema JW, Reymer PW, et al. Lipoprotein lipase activity is decreased in a large cohort of patients with coronary artery disease and is associated with changes in lipids and lipoproteins. J Lipid Res 1999;40:735-43.

19. Lee J, Tan CS, Chia KS, Tan CE, Chew SK, Ordovas JM, et al. The lipoprotein lipase S447X polymorphism and plasma lipids: interactions with APOE polymorphisms, smoking, and alcohol consumption. J Lipid Res 2004; 45:1132-9.

20. Salah D, Bohnet K, Gueguen R, Siest G, Visvikis S. Combined effects of lipoprotein lipase and apolipoprotein $\mathrm{E}$ polymorphisms on lipid and lipoprotein levels in the Stanislas cohort. J Lipid Res 1997;38:904-12.

21. Freeman DJ, Caslake MJ, Griffin BA, Hinnie J, Tan CE, Watson TD, et al. The effect of smoking on post-heparin lipoprotein and hepatic lipase, cholesteryl ester transfer protein and lecithin:cholesterol acyl transferase activities in human plasma. Eur J Clin Invest 1998;28:584-91.

22. Wilson K, Fry GL, Chappell DA, Sigmund CD, Medh JD. Macrophage-specific expression of human lipoprotein lipase accelerates atherosclerosis in transgenic apolipoprotein e knockout mice but not in C57BL/6 mice. Arterioscler Thromb Vasc Biol 2001;21:1809-15.

23. Fyfe T, Baxter RH, Cochran KM, Booth EM. Plasma-lipid changes after myocardial infarction. Lancet 1971; 2:997-1001.

24. McCall M, Elmfeldt D, Vedin A, Wilhelmsson C, Wedel $\mathrm{H}$, Wilhelmsen L. Influence of a myocardial infarction on blood pressure and serum cholesterol. Acta Med Scand 1979;206:477-81.

25. Yang $T$, Pang $C P$, Tsang MW, Lam CW, Poon PM, Chan LY, et al. Pathogenic mutations of the lipoprotein lipase gene in Chinese patients with hypertriglyceridemic type 2 diabetes. Hum Mutat 2003;21:453.

26. Kontula K, Aalto-Setala K, Kuusi T, Hamalainen L, Syvanen AC. Apolipoprotein E polymorphism determined by restriction enzyme analysis of DNA amplified by polymerase chain reaction: convenient alternative to phenotyping by isoelectric focusing. Clin Chem 1990; 36:2087-92.

27. Chen L, Baum L, Ng HK, Chan LY, Pang CP. Apolipoprotein $\mathrm{E}$ genotype and its pathological correlation in Chinese Alzheimer's disease with late onset. Hum Pathol 1999:30:1172-7.

28. Baroni MG, Berni A, Romeo S, Arca M, Tesorio T, Sorropago $G$, et al. Genetic study of common variants at the Apo E, Apo Al, Apo CIII, Apo B, lipoprotein lipase (LPL) and hepatic lipase (LIPC) genes and coronary artery disease (CAD): variation in LIPC gene associates with clinical outcomes in patients with established CAD. BCM Genet 2003;4:8.

29. Ferencak G, Pasalic D, Grskovic B, Cheng S, Fijal B, Sesto $M$, et al. Lipoprotein lipase gene polymorphisms in Croatian patients with coronary artery disease. Clin Chem Lab Med 2003;41:541-6.

30. Morrison AC, Ballantyne CM, Bray M, Chambless LE, Sharrett AR, Boerwinkle E. LPL polymorphism predicts stroke risk in men. Genet Epidemiol 2002;22:233-42.

31. van Bockxmeer FM, Liu Q, Mamotte C, Burke V, Taylor R. Lipoprotein lipase D9N, N291S and S447X polymorphisms: their influence on premature coronary heart disease and plasma lipids. Atherosclerosis 2001;157:123-9.

32. Zhao SP, Tong QG, Xiao ZJ, Cheng YC, Zhou HN, Nie S. The lipoprotein lipase Ser447Ter mutation and risk of stroke in the Chinese. Clin Chim Acta 2003;330:161-4.

33. Napolitano M, Blotta I, Montali A, Bravo E. 17 $\beta$-Estradiol enhances the flux of cholesterol through the cholesteryl ester cycle in human macrophages. Biosci Rep 2001; 21:637-52.

34. Damewood MD, Bellantoni JJ, Bachorik PS, Kimball AW Jr, Rock JA. Exogenous estrogen effect on lipid/lipoprotein cholesterol in transsexual males. J Endocrinol Invest 1989;12:449-54.

35. Mullick AE, Deckelbaum RJ, Goldberg IJ, Al-Haideri M, Rutledge JC. Apolipoprotein E and lipoprotein lipase increase triglyceride-rich particle binding but decrease particle penetration in arterial wall. Arterioscler Thromb Vasc Biol 2002;22:2080-5.

Received August 27, 2005, accepted December 1, 2005 